Supplementary Materials for:

\title{
Molecular Recognition at Model Organic Interfaces: Electrochemical Discrimination using Self-Assembled Monolayers (SAMs) Modified via the Fusion of Phospholipid Vesicles
}

\author{
Mariusz Twardowski and Ralph G. Nuzzo* \\ Department of Chemistry and the Frederick Seitz Materials Research Laboratory, \\ University of Illinois at Urbana-Champaign, Urbana, IL 61801
}

\footnotetext{
*Corresponding author

Phone: (217) 244-0809

Fax: (217) 244-2278

Email: r-nuzzo@uiuc.edu
} 
Supplementary Materials I

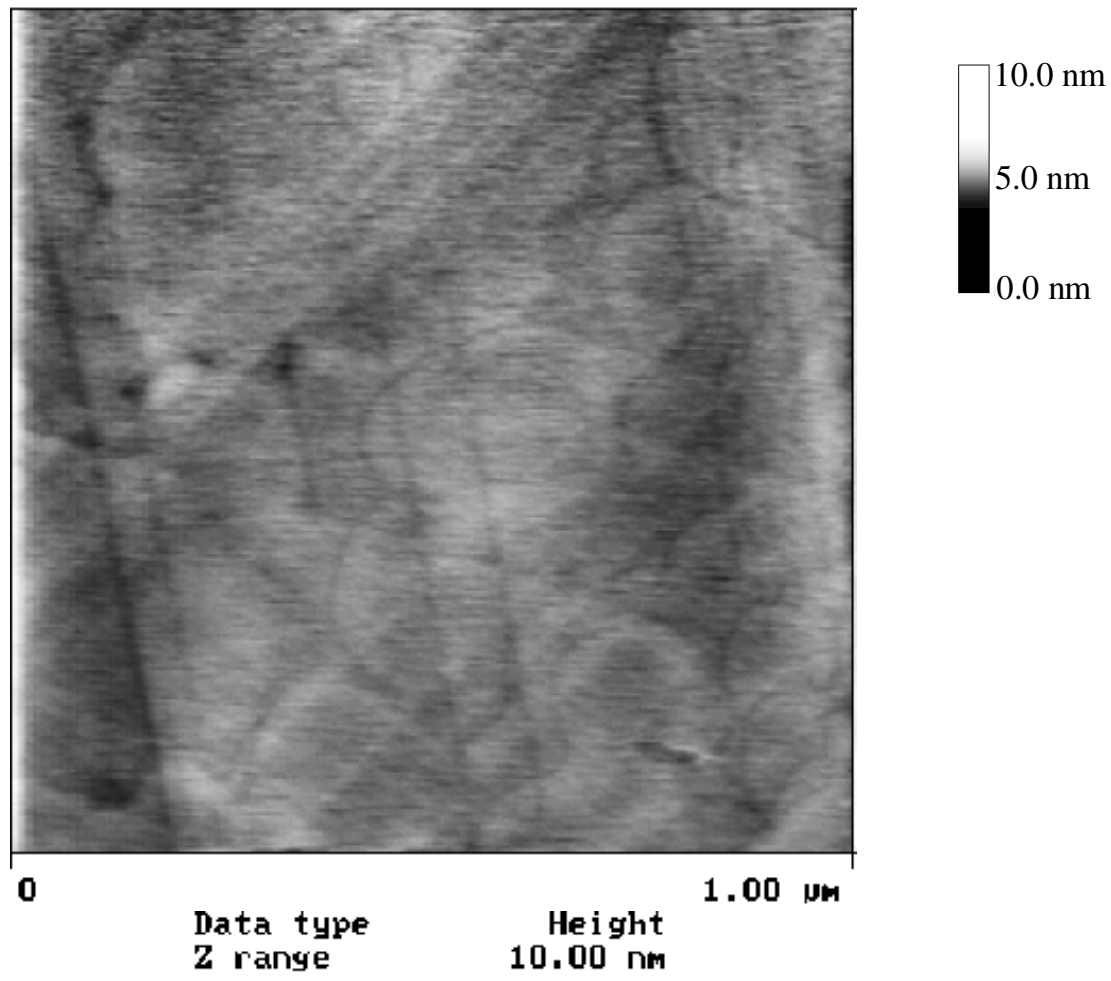

10101155. f03

AFM image of gold on mica substrate with $\mathrm{HOC}_{16}$ SH SAM 


\section{Supplementary Materials II}
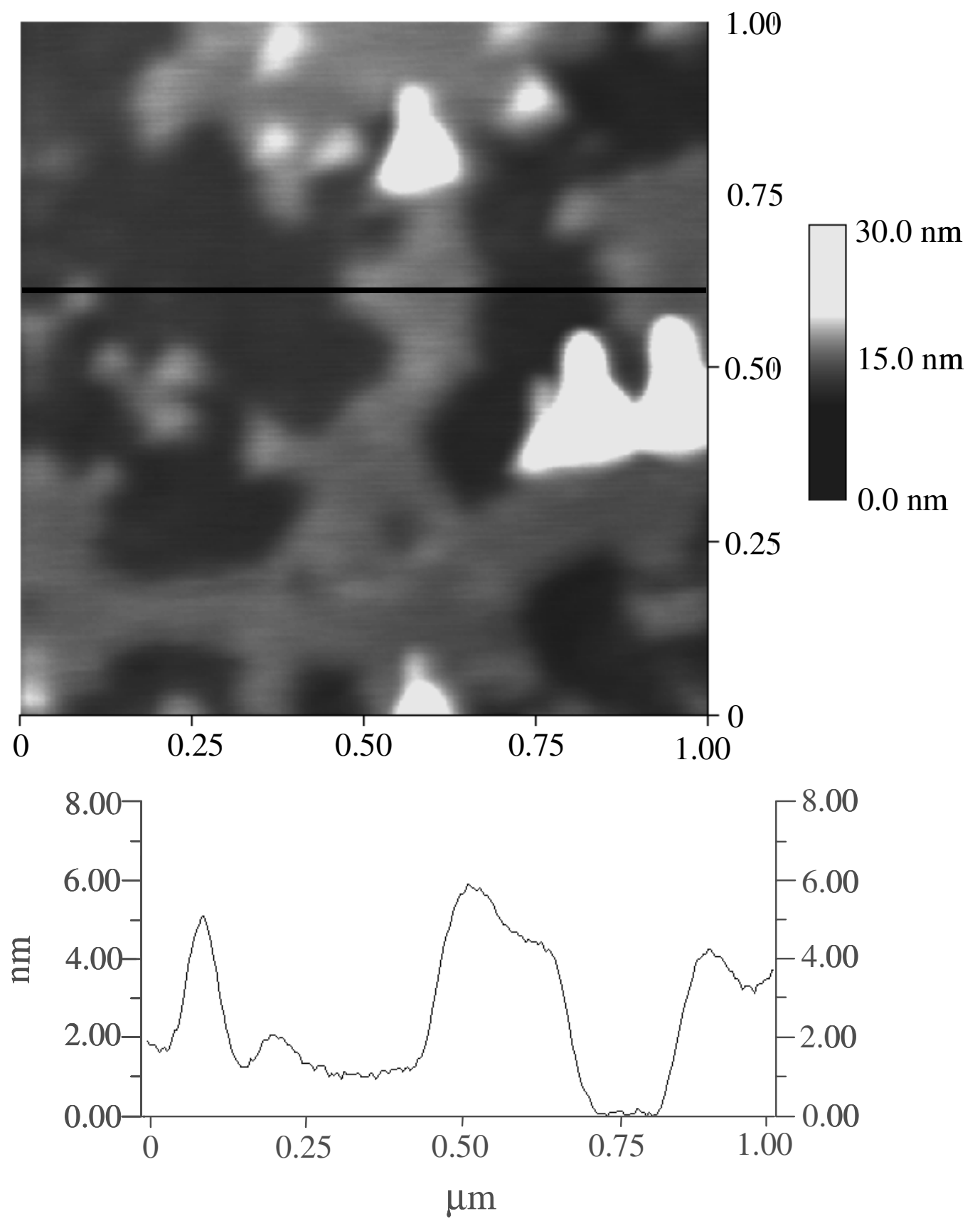

An AFM micrograph of the adsorbed lipid layer on a $\omega$-hydroxythiol SAM/gold substrate. The black bar corresponds to the cross section analysed in the height profile graph, which shows regions having height differences corresponding to one bilayer. The approximate $1 \mathrm{~nm}$ height differences present suggest a gel/liquid phase coexistence. 
